tember 1, by Dr. Aron of Berlin, "On the Telephone and Microphone." In this lecture the principles were explained on which the construction of the different telephones and microphones is based. There were also mentioned the variations of timbre as produced by these instruments; according to the experiments of Helmholtz the higher tones are transmitted better by the telephone, and therefore the timbre becomes clearer, while by the simple microphone, as Dr. Aron had found, the deeper tones are better transmitted, causing a duller timbre, but this failure is avoidable by using microphones with two coils, The lecturer explained also the principle of a new instrument, invented by himself, called the semaphone. In this instrument the variations of the current in a coil of insulated wire are transmitted by induction to another coil joined to a telephone or microphone. Dr. Aron has made experiments with his semaphone at Berlin, and was able to hear signals, the distance between the two coils being 70 feet. A similar experiment was carried out by Dr. Aron in the course of his lecture, and we could hear the noise made by a Neef's interrupter far from the lecture room, using a Siemens' telephone; the distance between the two coils being 3 feet.

Electric lighting is very well represented at the Exhibition, and a variety of new incandescent and arc lamps is to be seen there. As to the number of lamps exhibited, the first place is taken by the Swan lamps. Nearly 2000 Swan lamps are distributed at the theatre, the splendidly furnished interiors, and other parts of the building, fed by dynamo machines or by Faure-SellonVolckmar accumulators. The durability of these lamps is tested by a collection of lamps exhibited by Ganz and Co., used I720 to 2330 hours. The carbon filaments do not show any damage, only the glass bulb being darkened by a carbon deposit. The exhibition of Edison lamps is not so extensive as it was at previous exhibitions. The Maxim lamps are used for lighting the Oriental pavilion and some of the interiors. The Lane-Fox lamps are also lighting some furnished apartments, and show the applicability of incandescent lamps for street-lighting by lighting the "Ausstellungstrasse." The lamp of C. H. R. Miiller has a screw-like curled carbon filament to make the emission of rays uniform in all directions. The $U$-shaped carbon strap of the Greiner and Friedrich's incandescent lamp is preparcd from lamp-black and graphite, coal-tar being used as cement. The coal-tar, at first treated with sulphuric acid, is heated till it becomes an asphaltelike mass, to which lamp-black and graphite are then added, so that a stout paste is formed. By pressing this paste through a little fine hole a thin thread is obtained, which is cut in pieces and dried. If dried, the U-shaped pieces are burned. The carbonised fibres of Musa textilis are used for the incandescent lamps of Dr. Puluj. Very interesting is the Bernstein lamp, exhibited by the Bernstein Electric Light Manufacturing Company of Boston. It is claimed by the inventor to have many advantages over the other incandescent lamps. With an electromotive force of 23 volts and a current of 7 amperes, it has an illuminating power of 65 candles; it is stated to be more durable than the other lamps, and more economical, by rendering the light-giving carbon able to expand and contract without being liable to injury and breakage, and therefore capable of withstanding the action of strong currents, so as to avoid the disintegration which takes place in carbon filaments of high resistance. A large number of lamps can be used in series, and long distances can be lighted by means of a thin wire; the lamp is very appropriate for street-lighting. A hollow $U$-shaped carbon cylinder as big as a lucifer match is used as the light-giving part, having a comparatively large illuminating surface. This carbon cylinder is quite elastic, and its surface resembles knitwork. Though the manufacturing process of the carbon is not yet published, it seems to be very probable that the carbon cylinder is prepared by carbonising a hollow knitted or woven string, a metallic wire being put through during the burning process to support it. The ends of the $U$-shaped cylinder are connected with pear-like socket pieces of carbon, to which the two conducting wires are attached, entering the thin end of the carbon blocks, secured by means of it reddish cement. Such a lamp, fed by sixteen FaureVolckmar accumulators, gave, as could be seen at the lecture delivered by Sir William Siemens, a white, dazzling light resembling an arc lamp.

Vienna, September 10

\section{THE EDINBURGH BIOLOGICAL STATION}

$\mathrm{THE}$ proposal to form a biological station at Grantcr, which was some time ago brought before the Roy:l Society in a paper by Mr. Murray of the Challenger Commission, has now taken definite shape. A lease of Granton Quarry for fifteen years has just been granted by the Duke of Buccleuch at a nominal rent, and Mr. Alexander Turbyne, salmon fisber, has been appointed keeper of the station, and will enter on his duties next week Meantime some preliminary experiments have been made, and cages have been put down at the station, and structural work has been commenced in the way of fencing, building of walls, and putting the banks into proper order for further operations.

The proposal for the formation of the station, which it is meant to call "The Edinburgh Marine Station for Scientific Research," had its origin in the resolution of the Committee of the late Fisheries Exhibition in Edinburgh to hand over the surplus funds derived from the Exhibition to the Meteorological Society, to be applied to the purpose of carrying on investigations with respect to fish, with a recommendation to establish a zoological station, and to apply to Government for assistance in the work. The Meteorological Society appointed a subcommittee to consider the best means of applying this money to the purposes for which it was granted. This Committee had many consultations, and set afoot investigations at various ports as to the temperature of the water, habits and food of the fish, \&c. They also had their attention carefully directed to the advisability of establishing a zoological station; and the suitableness of the old quarry at Granton for the purpose has been in various ways brought before the public, both at the Royal Society and at the meetings of the Meteorological Society. The scheme for founding a station there first took definite shape on the offer of a gentleman interested in research to build a floating laboratory at the quarry for the purpose of making experiments and investigations. Recently this gentleman was again communicated with, in respect that, after full consideration, it was thought that a floating laboratory, although an essential part of the scheme, was not, ferhaps, the first that should be undertaken. In reply to a representation to this effect, the gentleman has written to $\mathrm{Mr}$. Murray, the convener of the Station Committee, expressing his readiness to adopt the alterations profosed, and to give the $1000 \mathrm{l}$. for the purpose of founding a zcological station for scientific research at Edinburgh, instead of building a floating laboratory, as originally suggested. He was not surprised to hear, he ards in his letter, that it would cost more than that to carry out the whole of the scheme. It seemed to him that they would require at least $1500 l$., in addition to his $1000 \%$., to carry out all their proposals, and they should consider if this additional sum should not be raised before they commenced orerations. However, he left the matter in the convener's hands to apply the money as he thought best, inclosing $100 /$. to cover preliminary expenses, and repeating the two conditions of his donation, viz. (I) that the convener should take the general direction of the station for at least three or four years; and (2) that his name was $r$ ot in the mean- 
time to be made public. The resolution which has now been come to is to go on with the undertaking, and the scheme is of a twofold character: (I) to undertake a scientific exploration and description of the Firth of Forth and the adjacent parts of the North Sea; and (2) to establish a marine station for biological investigation and research, where competent scientific men may find laboratories and all the appliances for research free of charge. With respect to the first branch of the scheme, it is meant to take the temperature of the water at fixed points of the Firth, extending from the fresh water of the Firth out to points beyond the Isle of May. The temperatures of the surface water and of the bottom and intermediate waters are to be taken at stated intervals throughout the year. It is part of the same scheme to note the character of the surface fauna and flora regularly throughout the year at these points, and the changes in the specific gravity of the water at the different times of the year and at different parts of the Firth. Observations will also be carefully laid down on the Admiralty charts of the nature of the bottom, and of the deposits, throughout the whole region, and a record of the animals living upon these is also to be attempted, so as to arrive at a complete scientific description of the bottom and its deposits. To this will be added a record of the effects upon the fauna, \&c., of the admixture of river and ocean water at different parts, and of circumstances favourable or inimical to life and growth. Under the second branch of the scheme the proposal is to establish at Granton Quarry, and at various places in the Firth, investigations as to the hatching, breeding, and growth of various kinds of fish and marine invertebrates in inclosed spaces, or in cages moored at various points. The central station will be situated at the quarry. Here it is proposed to build, on a high part of the banks surrounding the quarry, a substantial cottage, from which a beautiful view of the whole Firth will be had. The cottage is to be fitted up with laboratories, and will consist of about six rooms, and cost from $400 l$. to $500 l$. On a level piece of ground adjoining the quarry there will be erected an iron cottage and shed for the keeper of the station, and for housing the trawls, dredges, nets, and other instruments required for the proposed investigations. This will cost from $I_{5} \mathrm{ol}$. to $200 \mathrm{l}$. Also, as part of the scheme, there is to be built a floating laboratory - that is to say, a laboratory built on a barge of the description mentioned to the Royal Society, and supplied with all the materials and apparatus requisite for biological investigation. This structure, it is interesting to note, will be so fashioned that it may be taken to any part of the Firth of Forth, and moored in sheltered spots during the summer wher ever it may be thought desirable that investigations shal be carried on at any particular spot. This laboratory, it is intended, will give accommodation for three naturalists, with workrooms, and will cost about $800 \%$. The station furthermore, is to be provided with a steam launch fitted for dredging purposes and the making of hydrographic observations. The launch, according to the design, is to be built upon the plan of the steam pinnace that accompanied the Challenger during her cruise, but much larger, and will be provided with a separate engine for rolling in the dredges. This again will cost about $800 l$. In addition to these things there will be a small portable house belonging to the station, which may be put up on Inchkeith, Inchmickery, Inchcolm, or the Isle of May, should it be desirable to carry on any observations at these places. This, together with the cages formerly described for inclosing portions of the ocean and water of the quarry, will cost, it is estimated, about $300 l$. more. The fund which was granted by the Committee of the Fisheries Exhibition is to be applied, at the rate of $300 l$. a year for three or four years, to the keeping up of the station and the payment of the annual working expenses, including the salaries of a resident naturalist, an engineer, and a keeper. So that what is now wanted in order to the full equipment of the station is about $1500 \%$. to pay for the permanent works which are required before the station can be in complete working order. In the event of this sum being forthcoming at an early date, it is thought that the whole institution would be in working order next spring--probably by March or April.

It is bel eved by a number of our scientific men that an unciertaking of this kind, which will afford the means of making continuous observations into the circumstances which affect marine animals and plants-their food and their enemies-is the true method of getting the information necessary to settle many of the vexed questions with respect to the life histories of our food fishes, both of the salmon and sea fishes. The Firth of Forth yields special facilities for work of this kind. Thus, almost all our food fishes are frequenters of the Firth, and it is known to have a rich fauna, which has at various times been investigated by distinguished naturalists, as by Johnston of Berwick; Parnell, Allman, Forbes, Herdman, and others. A thorough investigation of the kind proposed will lead to great additions to knowledge, and will probably give the information that was wanted as to the evil effects or otherwise of trawling, which is one of the vexed questions at the present day. By directing their efforts to the thorough working out of a somewhat limited area like the Firth of Fortb, in its meteorological, hydrographical, and biological aspects, the Committee believe that more rapid progress will be made than by intermittent observations at widely separate points. Such a station will also be a great boon to naturalists who desire to work at any special subject. Naturalists are often deterred from undertaking investigations because of the difficulty of providing themselves with dredges, steamlaunch assistance, \&c. Here they will have these ready at hand whenever they choose to visit the station. So that, from this point of view, in addition to the purely scientific aspect of an undertaking of this kind, it probably will be found to bave a very wide economic bearing. The plans of the floating laboratory and of the other structures to which reference has been made are in the hands of Mr. Murray, from whom persons interested or desirous to aid in the carrying out of the scheme will receive every information they may wish to have.

\section{NOTES}

THE Directors of the Ben Nevis Observatory met on Thursday, 6th inst., and out of a list of nineteen applicants elected Mr. R. T. Omond, Edinburgh, Superintendent of the Observatory. Mr. Omond was a distinguished student of Edinburgh University, and for the past six or seven years has been chief assistant of Prof. Tait in conducting an extended series of physical experiments on the influence of pressure on deep-sea thermometers, the maximum density of water under different pressures, and cognate subjects of inquiry. The results of his work have been communicated in the form or papers to the Royal Society of Edinburgh. Mr. Omond's duties began from the above date; and shortly two assistants will be appointed, so that in October next a staff of three observers will have taken up their station at the Observatory, prepared to enter upon the work of the coming winter. The highest section of the bridle-road to the summit of the Ben was finished on Thursday at noon, and the first pair of horses which ever ascended the mountain made the ascent in the afternoon, carrying $2 \mathrm{cwt}$. each of building material. The building of the permanent Observatory commenced on the following day. A number of horses are employed carrying up material, and the Observatory is expected to be finished early next month. Arrangements are also being made for laying a telegraphic cable from Fort William 